To appear in Volume 17, Issue 8 (August 2017)

SpringerLink Header: Behavior (H Kirshner, Section Editor)

Topical Collection on Behavior

\title{
Current concepts of memory disorder in epilepsy: edging towards a network account
}

Genevieve Rayner ${ }^{1,2} \&$ Chris Tailby ${ }^{1,3}$

${ }^{1}$ Florey Institute of Neuroscience and Mental Health; Melbourne Brain Centre (Austin Campus), 245 Burgundy Street, Heidelberg VIC 3084 Australia

${ }^{2}$ Melbourne School of Psychological Sciences, The University of Melbourne; Parkville VIC 3010 Australia

${ }^{3}$ Institute of Social Neurosciences; Level 6, 10 Martin Street, Heidelberg VIC 3084 Australia

Corresponding author: Dr Genevieve Rayner, Florey Institute of Neuroscience and Mental Health, Melbourne Brain Centre (Austin Campus), 245 Burgundy Street, Heidelberg VIC 3084 Australia

Ph: +61 390357045

e: raynerg@unimelb.edu.au 


\section{Abstract}

Purpose of review: A paradigm shift in contemporary epileptology has been the reframing of both epilepsy and its comorbid memory disorders as the product of diseased brain networks. The current review discusses some of the clinical and theoretical implications that stem from this shift.

Recent findings: Some implications of a network conceputalisation of epilepsy include a need for more widespread cognitive phenotyping in epilepsy; recognition that memory disorders in epilepsy can be multi-determined, including by non-structural factors; deeper consideration given to the neurodevelopmental context in which memory problems emerge; the utility of new methods to characterise memory impairments in epilepsy; and a call for greater recognition of the close interrelationships between memory comorbidities and psychiatric symptoms in epilepsy.

Summary: Memory disorder significantly worsens the quality of life of people with epilepsy, underscoring the importance to patient wellbeing of giving due consideration to the up-to-date neuropsychological practises outlined in this review.

Keywords: memory; epilepsy; neuropsychology; phenotyping; brain networks; mood 


\section{Introduction}

It has long been recognised that memory impairments are a common comorbidity of epilepsy [1]. Historically, neurobiological understandings of human memory took a localisationist approach that focused on the integrity of the mesial temporal lobe. This was triggered by observations that bilateral removal or destruction of this region resulted in profound amnestic syndromes $[2,3]$. Of late, however, there has been a shift towards thinking of memory as the product of distributed, interconnected brain networks. This parallels the contemporary reconceptualisation of epilepsy as a network disease, as captured in a new classification system proposed by the International League Against Epilepsy (ILAE) in March 2017 [4]. In particular, the ILAE recasts epilepsy as a disease characterised by the rapid hypersynchrony of brain networks, with a predilection for networks involved in cognition [5]. As such neuropsychological comorbidities such as memory disorder are now considered an intrinsic part of the disease [4]. Of importance to patient wellbeing, that cognitive decrements undermine quality of life above and beyond the impact of seizures $[6,7]$ and thus require prompt recognition and remediation.

These new network-level concepts have major implications for how we view memory impairments in epilepsy. Using a narrative approach to synthesise the latest human research, this review seeks to reframe the common problem of memory in epilepsy through the lens of the new classification system. The results suggest that we may want to:

- Take a phenomenological or phenotypic approach to characterising memory decrement in people with epilepsy;

- Locate cognitive comorbidities within a neurodevelopmental framework i.e., consider the emergence and nature of memory problems relative to the stage of brain maturation when the network disease emerges;

- Consider new ways of examining memory network dysfunction in epilepsy;

- Explore the close relationship between memory impairments and psychiatric comorbidities

\section{Networks, network disease, and memory decrement in epilepsy}

The shift to thinking about epilepsy and its comorbidities as a product of network dysfunction is in keeping with contemporary models of brain function more broadly. The idea of intrinsic brain networks arguably has its origins in the "diagram makers" of classical aphasiology, whereby aphasias were viewed as stemming from disconnection between modules comprising a language-speech network [8]. In the era of modern neuroimaging this has evolved to a consideration of brain networks as ensembles of neurons, interconnected across a range of scales ( $\mathrm{mms}$ to $\mathrm{cms}$ ), and identifiable by their distributed patterns of covarying neural activity [9]. These networks are not independent of one another, but overlap and interact flexibly to support cognitive and behavioural demands [10]. Cognitive and affective processes are thus considered to be an emergent property of these networks, with behavioural disorder resulting from intra- and inter-network dysfunction [11].

In epilepsy, network disturbance can arise through various ætiologies, including structural pathologies, as well as genetic, immune, infectious, and metabolic causes 
[4]. The abnormal neuronal activity characteristic of the disease is thought to propagate along the brain's intrinsic functional networks, much as water will be channelled along the existing contours of a landscape. Network changes in epilepsy can occur across a range of scales, such that even abnormalities that appear localised at the structural level can influence network behaviour more broadly. For instance, hippocampal sclerosis is associated with focal neuronal loss. From a network perspective, this results not only in damage to a network node, but also undermines long-range network connections and leaves the sclerotic structure topographically isolated [12]. Distal network effects may also relate to behavioural phenomena such as reduced functioning of frontal cortices in people with temporal lobe epilepsy (TLE; for a review see [13]), or reduced capability to reconfigure network interactions that undermines cognitive performance [14]. This implies that in some cases even supposedly focal epileptogenic abnormalities can be linked to diffuse cognitive disease. Further, it appears that the broader network architecture of the brain can also be modified in an attempt to isolate ("firewall off") a focal epileptogenic abnormality [15], reducing the efficient routing of information around the brain during cognitive tasks $[15,16]$. Tantalizingly, it appears that simply changing the local configuration of a network can lead to focal epileptic phenomena, even in the absence of a focal epileptogenic 'oscillator' within the network [17]

Memory is an incredibly complex function involving the storage and retrieval of information, drawing upon a network of diverse brain regions. Key neuroanatomical hubs of the broader memory network have traditionally been inferred from clinical cases, where focal damage has resulted in characteristic patterns of memory deficit. Cortical regions typically included in this bilateral network are detailed in Table 1 [1, 17].

\section{INSERT TABLE 1 HERE}

The specific nature of the to-be-learned or recalled information influences which nodes of the memory network are recruited. For instance, the acquisition of verballypresented arbitrary paired associates will likely be a predominantly left-lateralised process, involving dIPFC, fusiform gyrus, parahippocampal and perirhinal cortices [1]. In contrast, autobiographic memories are rich in detail and emotion, and precisely located in time and place. Their complexity therefore engages the most widelydistributed expression of the network, encompassing all of the structures outlined above while simultaneously disengaging sensorimotor and external attention systems [18].

Reconceptualising memory as supported by large-scale networks, of which the mesial temporal lobe is but a part, also provides a neat explanation for observations regarding memory dysfunction in extra-temporal epilepsies such as frontal lobe epilepsy (FLE). Memory deficits in frontal lobe injury seem to derive from reduced organisation and strategic control of information [19], in keeping with a supervisory role of the prefrontal cortex within the memory network [20]. Higher-order deficits in cognitive control are common in FLE [21] and may secondarily undermine memory retrieval [22]. Accordingly, when patients with FLE are instructed to use strategies to 
compensate for executive dysfunction, episodic search and recall is often improved [23-25], a phenomenon not seen in the primary encoding deficits of TLE. The heterogeneity of memory dysfunction across people with epilepsy may indicate that different phenotypes of memory impairment relate to different network changes, and potentially different ætiological factors.

\section{Phenotypes, not phrenology}

While a focus on the mesial temporal lobes was fundamental to advancing our understanding of memory, it also led to what Baxendale and Thompson [26] characterise as an "almost phrenological" quest to link poor performances on memory tests to specific regions, or lateralisation, of the temporal lobe. While neuroanatomical specificity is crucial for disease focalisation or in making predictions about post-surgical cognitive outcomes, there has nonetheless been a shift towards considering non-anatomical factors that can affect memory test performances. For instance, a recent paper showed that amongst people with chronic focal epilepsy, the factors underpinning their exceedingly poor autobiographic memory depended on the timing of their disease onset [27]. Specifically, neurobiological factors such as younger age at onset, more frequent seizures, and reduced working memory had a strong association with autobiographic memory dysfunction in patients with earlyonset epilepsy, but memory impairment associated with late-onset epilepsy arose from psychological maladjustment as well as MRI-detected brain lesions [27]. Moreover, that the same cognitive outcome could stem from such diverse predictors in different subtypes of patients highlights the benefits of data-driven stratification of patients into homogenous sub-types, whereby distinctive clinical, demographic, cognitive, and psychological profiles are described separately for each group. Where possible these sub-types can be integrated with data regarding genomic variation and neuroimaging profile to create a rich, multimodal description of an epilepsy phenotypes $[28,29]$. Phenotypes have the benefit of being readily applied to clinical practice, as well as being easy to update as our knowledge evolves [30].

Using a phenotypic approach, Hermann and colleagues [31] used cluster analysis to group the neuropsychological performances of 92 people with TLE relative to that of 82 healthy controls, revealing three distinct cognitive phenotypes:

(1) Minimally impaired: $47 \%$ of people with TLE; small though significant structural changes relative to controls;

(2) Memory impaired; $24 \%$ of cases; moderate structural changes relative to controls, more pronounced than for the minimally impaired group and extending beyond mesial temporal region.

(3) Memory, executive, and speed impaired: $29 \%$ of cases; significantly older, longer epilepsy duration, and taking more AEDs than minimally impaired group; greater cognitive decrements over time than other clusters; most pronounced structural changes of all groups, with global effects.

Here, the individual components of each phenotype are richly described, and provide a more precise and comprehensive analysis of cognitive abnormalities in TLE than is possible when people with the condition are considered as a heterogeneous mass. Specifically, there is information in these phenotypes about clinical and neuroimaging 
characteristics, as well as more individualised prognostic information about cognitive outcome.

Neurocognitive markers specific to phenotypes also have the potential to identify specific brain networks altered by epilepsy. For instance, evidence of a semantic autobiographic memory deficit in a phenotype of FLE may indicate that their network disease disproportionately affects interactions concerning the anterior temporal aspect of the autobiographical memory system [22]. While this idea may touch on the 'phrenological' obsession described above, substituting focus for network, it does allow us to consider cognitive decrements as a function of deficient information exchange, rather than simply stemming from focal structural damage. Regardless, we hope that future research will provide clinicians with a guide to using neurocognitive markers to clarify the extent of the disease, with longitudinal tracking of phenotypes hopefully providing more individualised information about prognosis for use in patient counselling [31].

Neurocognitive phenotypes may also have the potential to inform treatment decisions. Although speculative, dysfunction in certain cognitive networks may provide clues as to the neurobiological systems implicated, and therefore which classes of anticonvulsant medication are most likely to succeed. In an example from psychiatry, weak activation of the cognitive control network in some people with major depression has been hypothesised to reflect an underlying dysregulation of the mesostriatal dopamine system [32], suggesting region-specific neurotransmitter systems that could be targeted pharmacotherapeutically. In an example from our own work in epilepsy [27], implications for treatment could take the form of prophylactic scholastic interventions that try to stave off abnormal cognitive network development in patients with early-onset epilepsy, and cognitive-behavioural or psychotropic therapies for treating memory dysfunction in late-onset epilepsies where patients endorse elevated levels of depressive symptoms. Once commenced on treatment, improvements in neuropsychological profiles may also provide a marker of treatment response.

\section{Memory disorder as a function of neurodevelopment}

Given that epilepsy can emerge at any stage of the lifespan [33], the search for ætiologies underpinning memory impairment must take a lifespan approach. This calls for careful mapping of the longitudinal trajectory of memory features relative to the natural course of the disease. Put more simply, did the onset of the disease disrupt the normal development of cognition-related brain networks (e.g., developmental dysplasia), or is it disrupting an otherwise normally developed system (e.g., post-stroke epilepsy in adulthood)?

Disruption to the immature brain can derail the normal trajectory of development, and result in the formation of aberrant functional networks (for a review see [34]). For instance, behavioural studies of adults with childhood-onset epilepsy reveal reduced cognitive skills suggestive of abnormal development of cognitive networks, patterns not replicated in epilepsy patients who experienced the onset of seizures in adulthood [27]. In a recent review of the literature on memory disturbance in children with epilepsy, $33 \%$ of reviewed studies suggested that risk of memory difficulties are 
greater for children with younger age of epilepsy onset [35]. More often, however, there was no impact of age at onset in these studies (52\%). A potential limiting factor is that these analyses are not nuanced enough to discern whether, rather than strict chronological age, greater cognitive vulnerability may specifically stem from the emergence of the disease at a critical phase of behavioural development. The timing of this critical phase may vary across children, especially in those who are neurologically unwell.

There is also a longstanding notion that some children with epilepsy can compensate for early brain insult by seemingly transferring memory function to an unaffected region of the brain, and that this capability depends on whether disease onset occurred before or after critical phases of memory network development (for a case study see [36]). In theory, when the disease declares itself before the memory system has finished developing, there is a greater opportunity for a compensatory shift to occur whereby the memory system flexibly re-routes to an undamaged node or region. When this shift is successful, performance on standard neuropsychological measures of memory as an adult will be normal despite evidence of longstanding pathology [1]. However more empirical evidence combining behavioural and functional neuroimaging techniques is needed to validate this phenomenon. Such research will need to reflect that the range of functional outcomes from early brain insult exists along a recovery continuum, where a child's outcome depends on both injury factors (severity, age at onset, duration of illness) and environmental influences (family, sociodemographic profile, access to interventions; [34]). As such, neurobiological, psychiatric, and cognitive factors will likely have a changing impact on memory function at different timings of disease onset [27].

\section{Innovative forms of memory assessment in epilepsy}

Increasing recognition that epilepsy can affect memory-related nodes and networks beyond the temporal lobes calls for new methods of assessment. Here we discuss three domains of memory not commonly assessed clinically, but which show initial promise in their ability to detect and perhaps treat memory problems.

Autobiographic memory. Autobiographic memory refers to the encoding, storage, and retrieval of events, people and places encountered across our lifetime [37].

Autobiographic recollection engages a large-scale iteration of the memory system encompassing midline, lateral cortical, and cerebellar regions [18] (Figure 1). Most studies of autobiographic memory in epilepsy have focused on TLE. They find that, relative to healthy controls, individuals with TLE consistently perform worse on autobiographic memory tests [38-40], recall less sensory information and emotion [41], and show reduced $\mathrm{FMRI}$ activation throughout the autobiographic memory network [42]. Of relevance to mental wellbeing, initial studies show that poor autobiographic memory is linked to an impoverished sense of self in patients with early onset mesial temporal epilepsy [43]. Autobiographic memory deficits in TLE were originally attributed to mesial temporal lobe pathology (e.g., [38,39]). More recently it has been suggested that another major mechanism may be recurrent, paroxysmal disturbance of the distributed autobiographic memory network caused by seizure activity or network disease [43], including from regions outside of the temporal lobes [21]. Neuroimaging studies suggest that the autobiographic memory 
network of people with focal epilepsy may be pathologically under-activated and under-engaged [45-51], particularly during seizures accompanied by impaired awareness [52-54]. Of relevance to clinical practice, the widely-distributed topography of the autobiographic memory network might explain the apparent sensitivity of autobiographical memory across epilepsy syndromes [22], suggesting potential utility as a marker of the extent/severity of network disease. There also is evidence from major depression that autobiographic memory impairment can be reversed once treatment restores network dynamics [55]. Such information could be a useful in planning patient management. Yet at present only $4 \%$ of neuropsychologists practicing in epilepsy centres include a measure of autobiographic memory in their standard psychometric work-up [56], suggesting that closer investigation into and dissemination of their clinical utility is warranted.

Music memory. Music-based memory is another domain with promise to improve neuropsychological practice in epilepsy. For instance, Wilson and Saling [57] studied the ability of patients with mesial TLE to learn musical paired associates, constructed analogous to arbitrary ('hard') and semantically related ('easy') verbal paired associates. Easy pairs consisted of a three note tonal motif, whereas hard pairs did not conform to a conventional scale and thus resulted in a jarring, unfamiliar nontonal motif. For easy musical pairs, the right mesial TLE group was impaired while the left mesial TLE group did not differ from controls. Both groups, however, were impaired on the hard musical pairs. This indicated that like in the verbal and spatial domains, lateralisation of music memory is task- rather than material-specific [57]. Expanding on this topic, Séverine Samson and colleagues have explored the impact of emotional salience on musical memory in epilepsy. They compared eight nonmusician mTLE patients with severe verbal memory impairments to healthy controls on a music memory task where stimuli were designed to elicit different emotions [58]. Patients were no different from controls in their ability to recall the sad, peaceful, and happy trials. However, their recognition of scary music was significantly impaired $(P<0.05)$, a finding replicated in MTLE patients who had undergone resective epilepsy surgery $(n=16$; [59]) and likely attributable to amygdala dysfunction [60]. The preservation of music memory (except for fear) contrasts with the patients' severe disturbances in verbal memory, as well as with Wilson and Saling's [57] findings of deficits on atonal pairs in $\mathrm{MTLE}$, and may suggest that the emotional salience of music is a protective factor for memory function. A topic for future research will be to examine whether the emotional power of music can be employed as a prophylactic or rehabilitative technique to support everyday memory function in people with epilepsy.

Prospection. Prospection is the ability to project ourselves into an imagined future, a form of mental time travel that underscores our ability to pursue goals by allowing us to construct fictional scenes to imagine what might happen in light of past experiences [61,62]. An intimate link between autobiographical memory and prospection is supposed on the basis of studies of amnestic patients in whom prospection is impaired [62], and the widespread recruitment of the autobiographic memory network during prospection [63] (Figure 1). The only study on prospective ability in epilepsy to date found that relative to healthy controls $(n=20)$, people with unilateral TLE $(n=20)$ generate less details when asked to describe potential 
autobiographical future events [64]. Although only preliminary data, these findings may indicate that assessment of a patient's prospective ability is clinically relevant to informed consent. Specifically, if a patient is known to struggle to mentally simulate a potential future set of circumstances, then we may need to reconsider -for examplepresurgical counselling. In such cases, clinicians may need to spend extra time with a patient to help them to generate richly detailed scenarios of potential future outcomes (e.g. a decline in verbal memory; changed family dynamics), and guide patients though what these alternative outcomes may mean for their quality of life.

\section{Memory disorders in the context of psychopathology}

In addition to memory decrement, people with epilepsy are also at significantly elevated risk of mood and anxiety disorders. Specifically, they have $43 \%$ higher odds of developing depression relative to healthy peers [65], and around $40 \%$ will ultimately experience a mood or anxiety disorder at some point in their lifetime $[66,67]$ as opposed to $17 \%$ of people from the broader community [68].

The symptoms of unipolar depression are believed to arise from abnormal dynamics between two cognition-related networks: the autobiographic memory network, and the cognitive control network (for an in-depth review, see [69]). Relevant to epilepsy, there is behavioural and neuroimaging evidence that seizures propagate along and alter the functioning of those two particular networks (see [70] for a recent review), with more extensive disease in memory networks seen in patients with depression. In particular, reduced new learning and delayed recall is most evident in TLE patients with either major depression or anxiety [71-73], with severity of depressive symptoms predictive of the severity of memory dysfunction [74]. More recent evidence indicates that patients with the worst performances on formal memory testing are those with depression in whom the depressive symptom profile reflects predominantly cognitive factors; that is, high rates of subjective cognitive difficulties, parasuicidal rumination, and delusions of worthlessness and guilt in addition to dysphoric mood [67]. Similarly, another recent study has shown that the lateralising information that might be provided by performances on auditory-verbal memory tests can be obscured in the presence of high levels of anxiety [75]. Of immediate clinical relevance, these findings reiterate that a patient's mood and anxiety state can significantly affect performances on psychometric testing; yet another marker of the multi-determined nature of cognitive functions.

At a more theoretical level, the links between mood and memory network dysfunction may signal a common network-based substrate in some cases of epilepsy. Crucially, the close interrelation of cognition and mood in epilepsy suggests that these functions may share neural substrates, and questions the utility of studying them as independent epiphenomena of epilepsy. This underscores the ILAE's emphasis on considering cognitive and psychiatric comorbidities as an intrinsic part of the network disease [4]. Given that depressive symptoms in epilepsy can often be effectively treated with psychological and pharmacological therapies [76,77], further research needs to investigate whether the alleviation of mood symptoms goes some way towards normalising the function of memory networks and memory test performances, as is seen after treatment with antidepressants like vortioxetine and modafinil in primary depression $[78,79]$. 
The important links between memory and mood in epilepsy are further illustrated by subjective memory complaints in this population. In the clinic, people with epilepsy frequently report that they feel far more 'forgetful' than they used to [80], with some feeling that it undermines their quality of life more so than the seizures [81]. While some studies have reported that the subjective memory complaints raised by people with epilepsy are concordant with difficulties on neuropsychological testing $[82,83]$, many more are unable to link subjective complaints to objective cognitive dysfunction [84-86]. The subjective memory complaints of people with epilepsy are actually more robustly attributed to psychiatric features that are frequently comorbid with epilepsy; namely depression, anxiety, and neurotic personality traits [87-89]. Here, subjective memory complaints likely reflect the cognitive inefficiencies that are intrinsic to affective disturbance [90] and the cognitive phenotype of depression in epilepsy more specifically [67], such as distractibility, reduced attention, and pathological rumination. Formal neuropsychological assessment may help differentiate between neurobiological and psychiatric explanations and inform treatment decisions [80]. There is also scope for further research investigating whether difficulties on more 'naturalistic' autobiographic memory measures might account for patient complaints better than do traditional memory tests used in the clinic.

\section{Conclusions}

Reframing epilepsy and its memory comorbidities as the product of network disease opens up many exciting new avenues for neuropsychological research and practice. Amidst the zeitgeist of 'precision medicine', it crystallises the concept that there are multiple pathways to memory dysfunction for individuals with epilepsy, and challenges clinicians and researchers to find robust ways to promptly detect and treat these dysfunctions and their causes so that we might optimise patient wellbeing.

\section{Acknowledgements}

We would like to thank Professor Graeme Jackson for his support, as well as our colleagues in the Comprehensive Epilepsy Programme at Austin Health. We would also like to acknowledge the support from a National Health and Medical Research Council project grant \#APP1081151.

\section{Conflict of Interest}

Genevieve Rayner and Chris Tailby each declare no potential conflicts of interest.

\section{Human and Animal Rights and Informed Consent}

This article does not contain any studies with human or animal subjects performed by any of the authors.

\section{References}

1. - Saling MM. Verbal memory in mesial temporal lobe epilepsy: beyond material specificity. Brain 2009;132:570-82. The author constructs a sophisticated critical analysis of the memory literature in epilepsy to form a neuroanatomical model of human memory 
2. Scoville WB, Milner B. Loss of recent memory after bilateral hippocampal sclerosis. J Neurol Neurosurg Psychiatry 1957;20:11-21.

3. Gadian DG, Aicardi J, Watkins KE, Porter DA, Mishkinm, Vargha-Khadem F. Developmental amnesia associated with early hypoxic-ischaemic injury. Brain 2000;123:499-507.

4. • Scheffer IE, Berkovic S, Capovilla G, Connolly MB, French J, Guilhoto L, Hirsch E, Jain S, Mathern GW, Moshé SL, Nordli DR. ILAE classification of the epilepsies: Position paper of the ILAE Commission for Classification and Terminology. Epilepsia 2017;28:512-21. This paper sets out the new classification system for epilepsy, in which epilepsy is reframed as a network disease of which neuropsychological comorbidities are a central feature

5. Berkovic SF, Jackson GD. 'Idiopathic' no more! Abnormal interaction of large-scale brain networks in generalized epilepsy. Brain 2014;137:2400-2.

6. Perrine K, Hermann BP, Meador KJ, Vickrey BG, Cramer JA, Hays RD, Devinsky O. The relationship of neuropsychological functioning to quality of life in epilepsy. Arch Neurol 1995;52:997-1003.

7. Giovagnoli AR, Parente A, Tarallo A, Casazza M, Franceschetti S, Avanzini G. Selfrated and assessed cognitive functions in epilepsy: impact on quality of life. Epilepsy Res 2014;108:1461-8.

8. Heilman KM. Aphasia and the diagram makers revisited: an update of information processing models. Journal of Clinical Neurology 2006;2:149-62.

9. Yeo BT, Krienen FM, Sepulcre J, Sabuncu MR, Lashkari D, Hollinshead M, Roffman JL, Smoller JW, Zöllei L, Polimeni JR, Fischl B. The organization of the human cerebral cortex estimated by intrinsic functional connectivity. J Neurophys. 2011;106:1125-65.

10. $\bullet$ Park HJ, Friston K. Structural and functional brain networks: from connections to cognition. Science 2013;342:1238411. An accessible discussion on how cognition can be thought of as the product of brain networks

11. Sporns O. The human connectome: a complex network. Ann NY Acad Sci 2011;1224:109-25.

12. Vaughan DN, Rayner G, Tailby C, Jackson GD. MRI-negative Temporal Lobe Epilepsy: a network disorder of neocortical connectivity. Neurology 2016;87:1934-42.

13. Stretton J, Thompson PJ. Frontal lobe function in temporal lobe epilepsy. Epilepsy Res. 2012;98:1-3.

14. Tailby C, Jackson GD. Cognitive impairment in epilepsy as disruption of taskdependent network reconfiguration. Abstract accepted as a poster by the Organisation for Human Brain Mapping Annual Meeting 2016.

15. Pedersen M, Omidvarnia AH, Walz JM, Jackson GD. Increased segregation of brain networks in focal epilepsy: an fMRI graph theory finding. Neurolmage Clin. 2015;8:536-42.

16. •-Stam CM. Epilepsy: What can we learn from modern network theories? Epileptologie 2016;33:38-43. The author presents a clear discussion of some of the issues stemming from the move towards a network approach to epilepsy, and the implications of this for cognition and behaviour

17. Terry JR, Benjamin O, Richardson MP. Seizure generation: the role of nodes and networks. Epilepsia. 2012;53:e166-9. 
18. Tailby C*, Rayner G*, Wilson S, Jackson G. The spatiotemporal substrates of autobiographical recollection: Using event-related ICA to study cognitive networks in action. Neurolmage 2017;152:237-48.

19. Baldo JV, Shimamura AP. Frontal lobes and memory. In: Baddeley AD, Kopelman MD, Wilson BA, editors. The handbook of memory disorders. Chichester: John Wiley \& Sons, Ltd; 2002. pp. 363-79.

20. Budson AE, Price BH. Memory dysfunction. N Engl J Med 2005;352:692-9.

21. O'Muircheartaigh J, Richardson MP. Epilepsy and the frontal lobes. Cortex 2012;48:144-55.

22. Rayner G, Jackson GD, Wilson SJ. Behavioral profiles in frontal lobe epilepsy: Autobiographic memory versus mood impairment. Epilepsia 2015;56:225-33.

23. Drane DL, Lee GP, Cech H, Huthwaite JS, Ojemann GA, Ojemann JG, Loring DW, Meador KJ. Structured cueing on a semantic fluency task differentiates patients with temporal versus frontal lobe seizure onset. Epilepsy Behav 2006;9:339-44.

24. McKinnon MC, Nica El, Sengdy P, Kovacevic N, Moscovitch M, Freedman M, Miller BL, Black SE, Levine B. Autobiographical memory and patterns of brain atrophy in fronto-temporal lobar degeneration. J Cogn Neurosci 2008;20:1839-53.

25. Thaiss $L$, Petrides $M$. Autobiographical memory of the recent past following frontal cortex or temporal lobe excisions. Eur J Neurosci 2008;28:829-40.

26. Baxendale S, Thompson P. The new approach to epilepsy classification: Cognition and behavior in adult epilepsy syndromes. Epilepsy Behav 2016:64;318-21.

27. $\bullet$ Rayner G, Jackson GD, Wilson SJ. Mechanisms of memory impairment in epilepsy depend on age at disease onset. Neurology 2016;87:1642-9. This study examines predictors of autobiographic memory dysfunction for patients grouped by the timing of disease onset, combining the phenotyping and neurodevelopment approaches advocated in this review

28. Insel T, Cuthbert B, Garvey M, Heinssen R, Pine DS, Quinn K, Sanislow C, Wang P. Research domain criteria (RDoC): toward a new classification framework for research on mental disorders. Am J Psychiatry 2010;167:748-51.

29. Robinson PN. Deep phenotyping for precision medicine. Hum Mutat 2012;33:777-80.

30. Berg AT, Berkovic SF, Brodie MJ, Buchhalter J, Cross JH, van Emde Boas W, Engel J, French J, Glauser TA, Mathern GW, Moshé SL, Nordli D, Plouin P, Scheffer IE. Revised terminology and concepts for organization of seizures and epilepsies: report of the ILAE Commission on Classification and Terminology, 2005-2009. Epilepsia 2010;51:676-85.

31. $\bullet$ Hermann B, Seidenberg M, Lee EJ, Chan F, Rutecki P. Cognitive phenotypes in temporal lobe epilepsy. J Int Neuropsychol Soc 2007;13:12-20. This study was the first to describe cognitive phenotypes of epilepsy, setting the benchmark for this important research technique

32. Hamilton JP, Chen G, Thomason ME, Schwartz ME, Gotlib IH. Investigating neural primacy in Major Depressive Disorder: multivariate Granger causality analysis of resting-state fMRI time-series data. Mol Psychiatry. 2011;16:763-72.

33. Olafsson E, Ludvigsson P, Hesdorffer D, Kjartansson O, Hauser WA, Gudmundsson $G$. Incidence of unprovoked seizures and epilepsy in Iceland and assessment of 
the epilepsy syndrome classification: a prospective study. Lancet Neurol 2005;4:627-34.

34. Anderson V, Spencer-Smith M, Wood A. Do children really recover better? Neurobehavioural plasticity after early brain insult. Brain 2011;134:2197-21.

35. Menlove L, Reilly C. Memory in children with epilepsy: A systematic review. Seizure 2015;25:126-35.

36. Wood AG, Saling MM, O'Shea MF, Jackson GD, Berkovic SF. Reorganization of verbal memory and language: a case of dissociation. J Int Neuropsychol Soc 1999;5:69-74.

37. Wheeler MA, Stuss DT, Tulving E. Toward a theory of episodic memory: the frontal lobes and autonoetic consciousness. Psychological Bull 1997;121:331-54.

38. Buchanan TW, Tranel D, Adolphs R. Memories for emotional autobiographical events following unilateral damage to medial temporal lobe. Brain 2006;129:115-27.

39. Noulhiane M, Piolino P, Hasboun D, Clemenceau S, Baulac M, Samson S. Autobiographical memory after temporal lobe resection: neuropsychological and MRI volumetric findings. Brain 2007;130:3184-99.

40. Herfurth K, Kasper B, Schwarz M, Stefan H, Pauli E. Autobiographical memory in temporal lobe epilepsy: role of hippocampal and temporal lateral structures. Epilepsy Behav 2010;19:365-71.

41. St Laurent M, Moscovitch M, Levine B, McAndrews MP. Determinants of autobiographical memory in patients with unilateral temporal lobe epilepsy or excisions. Neuropsychologia 2009;47:2211-21.

42. Addis DR, Moscovitch M, McAndrews MP. Consequences of hippocampal damage across the autobiographical memory network in left temporal lobe epilepsy. Brain 2007;130:2327-42.

43. Allebone J, Rayner G, Siveges B, Wilson SJ. Altered self-identity and autobiographical memory in epilepsy. Epilepsia 2015;56:1982-91.

44. Voltzenlogel V, Despres O, Vignal J-P, Kehrli P, Manning L. One-year postoperative autobiographical memory following unilateral temporal lobectomy for control of intractable epilepsy. Epilepsia 2007;48:605-8.

45. Laufs H, Hamandi K, Salek-Haddadi A, Kleinschmidt AK, Duncan JS, Lemieux L. Temporal lobe interictal epileptic discharges affect cerebral activity in 'default mode' brain regions. Hum Brain Mapp 2007;28:1023-32.

46. Frings L, Schulze-Bonhage A, Spreer J, Wagner K. Remote effects of hippocampal damage on default network connectivity in the human brain. J Neurol 2009;256:2021-9.

47. Liao W, Zhang Z, Pan Z, Mantini D, Ding J, Duan X, Luo C, Lu G, Chen H. Altered functional connectivity and small-world in mesial temporal lobe epilepsy. PLoS ONE 2010;5:e8525.

48. Liao W, Zhang Z, Pan Z, Mantini D, Ding J, Duan X, Luo C, Wang Z, Tan Q, Lu G, Chen $\mathrm{H}$. Default mode network abnormalities in mesial temporal lobe epilepsy: A study combining fMRI and DTI. Hum Brain Mapp 2011;32:883-95.

49. Pittau F, Grova C, Moeller F, Dubeau F, Gotman J. Patterns of altered functional connectivity in mesial temporal lobe epilepsy. Epilepsia 2012;53:1013-23.

50. Voets NL, Beckmann CF, Cole DM, et al. Structural substrates for resting network disruption in temporal lobe epilepsy. Brain 2012; 13: 2350-2357. 
51. Centeno M, Perani K, St Pier K, et al. Default mode network dysfunction in a patient with epilepsy in the precuneus. American Epilepsy Society Annual Meeting. Washington, USA; 2013.

52. Blumenfeld H, McNally KA, Vanderhill SD, Paige AL, Chung R, Davis K, Norden AD, Stokking R, Studholme C, Novotny EJ, Zubal IG. Positive and negative network correlations in temporal lobe epilepsy. Cereb Cortex 2004;14:892-902.

53. Danielson NB, Guo JN, Blumenfeld $H$. The default mode network and altered consciousness in epilepsy. Behav Neurol 2011;24:55-65.

54. Cataldi M, Avoli M, de Villers-Sidani E. Resting state networks in temporal lobe epilepsy. Epilepsia 2013;54:2048-59.

55. Young KD, Siegle GJ, Zotev V, Phillips R, Misaki M, Yuan H, Drevets WC, Bodurka J. Randomized clinical trial of real-time fMRI amygdala neurofeedback for major depressive disorder: effects on symptoms and autobiographical memory recall. Am J Psychiatry. 2017;4: dx.doi.org/10.1176/appi.ajp.2017.16060637.

56. Djordjevic J, Jones-Gotman M. Inquiry on assessments across epilepsy centers in different countries. In: Helmstaedter C, Hermann B, Lassonde M, Kahane P, editors. Neuropsychology in the Care of People with Epilepsy. Montrouge, France: John Libbey Eurotext; 2011:13-26.

57. Wilson SJ, Saling MM. Contributions of the right and left mesial temporal lobes to music memory: Evidence from melodic learning difficulties. Music Percept 2008;25:12.

58. Samson S, Dellacherie D, Platel H. Emotional power of music in patients with memory disorders. Ann NY Acad Sci 2009;1169:245-55.

59. Gosselin N, Peretz I, Noulhiane M, Hasboun D, Beckett C, Baulac M, Samson S. Impaired recognition of scary music following unilateral temporal lobe excision. Brain 2005;128:628-40.

60. Duvarci S, Pare D. Amygdala microcircuits controlling learned fear. Neuron 2014;82:966-80.

61. Tulving E. Episodic memory: from mind to brain. Annu Rev Psychol 2002;53:1-25.

62. Hassabis D, Maguire EA. Deconstructing episodic memory with construction. Trends Cogn Sci 2007;11:299-306.

63. Schacter DL, Addis DR, Buckner RL. Remembering the past to imagine the future: the prospective brain. Nat Rev Neurosci. 2007;8:657-61.

64. Lechowicz M, Miller L, Irish M, Addis DR, Mohamed A, Lah S. Imagining future events in patients with unilateral temporal lobe epilepsy. Br J Clin Psychol 2016;55:187-205.

65. Fuller-Thomson E, Brennenstuhl S. The association between depression and epilepsy in a nationally representative sample. Epilepsia 2009;50:1051-8.

66. Adams SJ, O'Brien TJ, Lloyd J, Kilpatrick CJ, Salzberg MR, Velakoulis D. Neuropsychiatric morbidity in focal epilepsy. Br J Psychiatry 2008;192:464-9.

67. Rayner G, Jackson GD, Wilson SJ. Two distinct symptom-based phenotypes of depression in epilepsy yield specific clinical and etiological insights. Epilepsy Behav 2016;64:336-44.

68. Australian Bureau of Statistics (ABS) 2008. National survey of mental health and wellbeing: summary of results, Australia, 2007. ABS cat. no. 4326.0. Canberra: ABS. 
69. Rayner G, Jackson GD, Wilson SJ. Cognition-related brain networks underpin the symptomotology of unipolar depression: evidence from a systematic review. Neurosci Biobehav Rev 2016;61;53-65.

70. Rayner $\mathrm{G}$. The contribution of cognitive networks to depression in epilepsy. Epilepsy Curr 2017;2:78-83.

71. Brown FC, Westerveld M, Langfitt JT, Hamberger M, Hamid H, Shinnar S, Sperling MR, Devinsky O, Barr W, Tracy J, Masur D. Influence of anxiety on memory performance in temporal lobe epilepsy. Epilepsy Behav 2014;31:19-24.

72. Paradiso S, Hermann BP, Blumer DP, Davies K, Robinson RG. Impact of depressed mood on neuropsychological status in temporal lobe epilepsy. J Neurol Neurosurg Psychiatry 2001;70:180-5.

73. Helmstaedter C, Sonntag-Dillender M, Hoppe C, Elger C. Depressed mood and memory impairment in temporal lobe epilepsy as a function lateralization and localization. Epilepsy Behav 2004;5:696-701.

74. Dulay MF, Schefft BK, Fargo JD, Privitera MD, Yeh H. Severity of depressive symptoms, hippocampal sclerosis, auditory memory, and side of seizure focus in temporal lobe epilepsy. Epilepsy Behav 2004;5:522-31.

75. Brown FC, Westerveld M, Langfitt JT, Hamberger M, Hamid H, Shinnar S, Sperling MR, Devinsky O, Barr W, Tracy J, Masur D. Influence of anxiety on memory performance in temporal lobe epilepsy. Epilepsy Behav. 2014;31:19-24.

76. Gandy M, Sharpe L, Perry KN. Cognitive behavior therapy for depression in people with epilepsy: a systematic review. Epilepsia 2013;54:1725-34.

77. $\bullet$ Kanner AM. Most antidepressant drugs are safe for patients with epilepsy at therapeutic doses: a review of the evidence. Epilepsy Behav 2016;61282-6. A review to reassure physicians as to the safety in prescribing antidepressant drugs for people with epilepsy

78. DeBattista C, Lembke A, Solvason HB, Ghebremichael R, Poirier J. A prospective trial of modafinil as an adjunctive treatment of major depression. J Clin Psychopharmacol 2004;24:87-90.

79. McIntyre RS, Lophaven S, Olsen CK. A randomized, double-blind, placebocontrolled study of vortioxetine on cognitive function in depressed adults. Int J Neuropsychopharmacol 2014;17:1557-67.

80. Rayner G, Wrench JM, Wilson SJ. Differential contributions of objective memory and mood to subjective memory complaints in refractory focal epilepsy. Epilepsy Behav 2010;19:359-64.

81. Fisher RS, Vickrey BG, Gibson P, Hermann B, Penovich P, Scherer A, Walker S. The impact of epilepsy from the patient's perspective I. Descriptions and subjective perceptions. Epilepsy Res 2000;41:39-51.

82. Giovagnoli AR, Avanzini G. Quality of life and memory performance in patients with temporal lobe epilepsy. Acta Neurol Scand 2000;101:295-300.

83. Marques CM, Caboclo LOSF, da Silva TI, da Silva Noffs MH, Carrete H Jr, Lin K, Lin J, Sakamoto AC, Yacubian EM. Cognitive decline in temporal lobe epilepsy due to unilateral hippocampal sclerosis. Epilepsy Behav 2007;10:477-85.

84. Au A, Leung P, Kwok A, Li P, Lui C, Chan J. Subjective memory and mood of Hong Kong Chinese adults with epilepsy. Epilepsy Behav 2006;9:68-72. 
85. Baños JH, LaGory J, Sawrie S, Faught E, Knowlton R, Prasad A, Kuzniecky R, Martin RC. Self-report of cognitive abilities in temporal lobe epilepsy: cognitive, psychosocial, and emotional factors. Epilepsy Behav 2004;5:575-9.

86. Piazzini A, Canevini MP, Maggiori G, Canger R. The perception of memory failures in patients with epilepsy. Eur J Neurol 2001;8:613-20.

87. Grewe P, Nikstat A, Koch O, Koch-Stoecker S, Bien CG. Subjective memory complaints in patients with epilepsy: The role of depression, psychological distress, and attentional functions. Epilepsy Res 2016;127:78-86.

88. Hendriks MPH, Aldenkamp AP, van der Vlugt $\mathrm{H}$, Alpherts WC, Vermeulen J. Memory complaints in medically refractory epilepsy: relationship to epilepsyrelated factors. Epilepsy Behav 2002;3:165-72.

89. Witt J-A, Glöckner C, Helmstaedter C. Extended retention intervals can help to bridge the gap between subjective and objective memory impairment. Seizure 2012;21:134-40.

90. Beck AT. The evolution of the cognitive model of depression and its neurobiological correlates. American Journal of Psychiatry 2008;165:969-77.

Figure 1. Activation patterns during an autobiographical recollection task (left; see [18]) and a prospection task (right), as observed across nine participants. Direct statistical comparison of these activation patterns reveals no significant differences, reflecting the similarity of the systems recruited during autobiographical recollection and prospection. 
Table 1. Components of the bilateral memory network

\begin{tabular}{ll} 
Region & Contribution to memory \\
\hline Hippocampal and parahippocampal areas & $\begin{array}{l}\text { arbitrary association; encoding and } \\
\text { consolidation }\end{array}$ \\
\hline Anterolateral temporal cortex & semantic associations \\
$\begin{array}{l}\text { Prefrontal cortices, especially mesial } \\
\text { (mPFC), ventrolateral (vlPFC), and }\end{array}$ & $\begin{array}{l}\text { self-reflection, social cognition, emotional } \\
\text { processing, cognitive control }\end{array}$ \\
dorsolateral (dIPFC) portions & higher-order contextual schemas for \\
Retrosplenial and posterior cingulate & efficient coding \\
cortices & attentional aspects of memory search \\
\hline
\end{tabular}

